\title{
Optimal Coordination of Overcurrent Relays in the Presence of Distributed Generation Using an Adaptive Method
}

\author{
Reza Mohammadi ${ }^{\dagger}$, Meysam Farrokhifar*, Hossein Askarian Abyaneh** and Ehsan Khoob**
}

\begin{abstract}
The installation of distributed generation (DG) in the electrical networks has numerous advantages. However, connecting and disconnecting of DGs (CADD) leads to some problems in coordination of protection devices due to the changes in the short circuit levels in the different points of network. In this paper, an adaptive method is proposed based on available setting groups (SG) of relays. Since the number of available SG is less than possible CADD states, a classifying index (CI) is defined to categorize the several states in restricted setting groups. Genetic algorithm (GA) with a suitable objective function (OF) is used as an optimization method for the classification. After grouping, a modified coordination method is applied to achieve optimal coordination for each group. The efficiency of the proposed technique is demonstrated by simulation results.
\end{abstract}

Keywords: Adaptive protection, Overcurrent relay, Distributed generation, Optimal coordination

\section{Introduction}

In recent years, due to the increased consumption demand of electrical energy, use of distributed generation resources to feed electrical loads has increased [1]. The use of these sources in the distribution system network has many benefits. However, installing DG causes to some problems in the distribution network protection. The fault current injected from DG leads to changes in the short circuit current levels in the various points of the network. So the coordination of overcurrent protective devices may disturb because of changes in value and direction of fault currents [2].

The magnitude of fault current injected from DG to the network and the impact of DG on the network protection, depends on the technology type of DG. Three main types of DGs are synchronous generators, induction generators and inverter based generators. The synchronous based DGs commonly have the highest fault current, and the inverter based DGs have the lowest fault current level. This study concentrates on the synchronous generators which have a significant impact on the protection coordination of distribution network.

In the previous papers, several methods have been proposed to solve the coordination problem of overcurrent relays and other protective devices in presence of DGs. In [3-5], the impact of DG on the distribution system protection is studied, and some solutions are suggested, which assess the protection device coordination when a

$\dagger$ Corresponding Author: Dept. of Electrical Engineering, Shahid Beheshti University, A.C., Iran. (Rmohammadi@pwut.ac.ir)

* Dept. of Electrical Engineering, Islamic Azad University, Heris Branch, Iran. (farrokhifar@herisiau.ac.ir)

** Dept. of Electrical Engineering, Amirkabir University of Technology, Iran. (askarian@aut.ac.ir, Ehsan.khoob@gmail.com)

Received: September 7, 2015; Accepted: July 26, 2016 new DG is installed. The methods are based on changing protective devices or modifying the setting of them in the presence of DGs. [6] proposes an algorithm for overcurrent relays coordination in the presence of DG. This method uses directional overcurrent relays to overcome the impact of DG on distribution network protection.

In [7], fault current limiter (FCL) is proposed for limiting the impact of DGs on the protection of the network. Furthermore, some methods for calculation of the FCL impedance is presented in [8,9] and [10] to limit the effect of DGs. It seems that with commercialization of FCL, in the future, this method can be more applicable.

An adaptive protection method is developed in [11] to prevent disconnecting of all DGs. This solution is an effective method, but due to change in network structure, needs to spend high initial costs for special breakers, measurement equipment, communication links, and substation computer [5].

In [12], an adaptive protection method is used to mitigate the impact of DG on overcurrent (OC) relay protection by updating the $\mathrm{OC}$ relay minimum pickup current. Microprocessor-based recloser is used to coordinate fuse and recloser with installing DG [13]. Also, a simple adaptive overcurrent protection using two setting groups is proposed for two states of network; islanded and gridconnected modes [14]. The mentioned papers concentrate on the solution to a specific protection performance. In [15], an approach is presented which the settings of relays is calculated online after each change in power system topology. Also, a multi-agent system is used for coordination in presence of DG [16]. These methods require some infrastructures for online calculations and applying new settings of relays.

A network-enabled adaptive OC protection is proposed to overcome the DGs-imposed technical challenges such 
as; increase of fault current, sympathy tripping, and unintentional islanding [17]. Also, an adaptive protection scheme is proposed to amend the protection settings of overcurrent relays in response to the various network scenarios, including CADD states. The new protection settings are sent to the OC relays, which compliant with IEC61850, using two approaches; with setting groups or without predefined setting groups [18].

The use of predefined setting groups causes to limit the relay setting, but have some advantages such as; avoiding the frequent change of protection setting, reducing the risk of applying wrong settings to relays, and the availability in several types of relays. The mentioned adaptive methods have not presented approach for OC relay protection of networks (with several network scenarios) using the limited setting group. In [19], an adaptive method is proposed that uses available relay setting groups to overcome miss-coordinations, which appear because of CADD. In each state of CADD, if the change of relay setting is necessary to restore the coordination, the new setting group from available setting groups of relay is assigned. Since the available setting groups of relays are less than the number of CADD states, it is impossible to give a setting group for all states. If extra setting groups is needed for coordination of relays in the new states, the previously used setting groups are assigned. In [19], the priority and similarity of CADD states are not considered in assignment of setting groups. With an increase in the number of DGs which cause to exponential increase in the CADD states, it is difficult to achieve full coordination without optimal assignment of CADD states.

The gap that this paper intends to fill is presenting a method for considering the practical limitations in implementation of adaptive methods. In adaptive methods, because of avoiding of frequent change in overcurrent relays settings or using the limited setting groups of relays, a method is required for classification of states. Therefore, in this paper a classifying index is defined to determine the similarity of CADD states, and a classifying method is proposed to achieve optimal selection of similar states. In this method a suitable look up table is obtained to settle on appropriate setting groups of relays for each CADD state. Also, the coordination method is modified to obtain the optimal setting of relays in multiple CADD states with multiple short circuit currents.

Finally, to determine the effectiveness of the proposed approach, appropriate simulations are carried out on IEEE 30 bus network, and the results of new method are compared with previous method's results.

\section{Problem Statement}

Because of variable load demand in various times of day and different seasons of year, the variable power of renewable energy sources and especially nowadays with

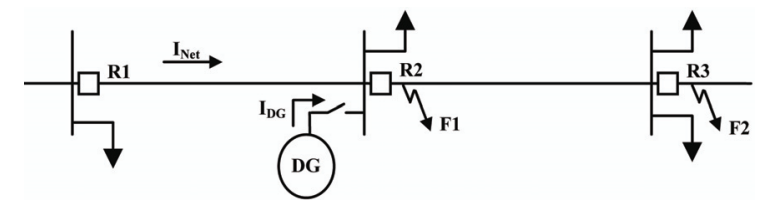

Fig. 1. Sample network with one installed DG

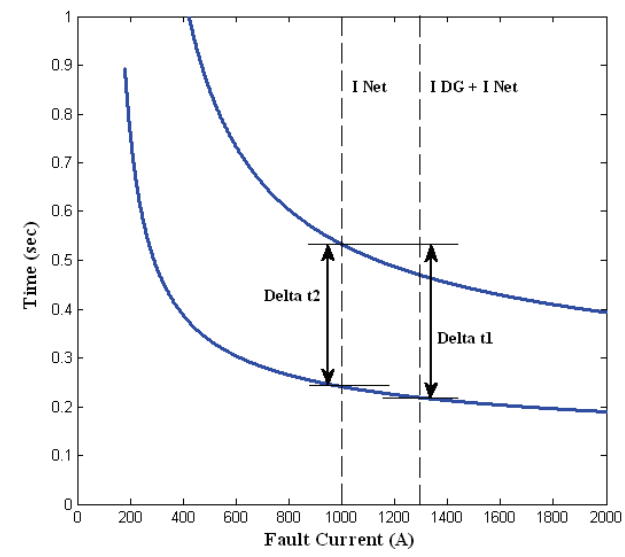

Fig. 2. The time interval between relays $\mathrm{R} 1 \& \mathrm{R} 2$

the private owner of distributed generation and economic problem, the numerous connecting or disconnecting of DGs to the network are inevitable. This leads to changes in fault current passes through the main and backup (M/B) relays. Therefore, the coordination of relays, which are considered with the fixed settings, is disturbed in different states of DG connections.

This problem is described with Fig. 1 in the presence of one DG.

In order to describe the impact of CADD on the coordination of three relays R1, R2 and R3, two states can be considered as below:

It is assumed that the coordination of relays is carried out in the presence of DG. If the DG is disconnected from network, the coordination between relays R1 and R2 will be disturbed for the fault occurring in F1 (Fig. 2).

As can be seen from Fig. 2, unlike R1 (whose fault current $\left(\mathrm{I}_{\mathrm{Net}}\right)$ remains without change), the fault current of R2 decreases from $I_{D G}+I_{N e t}$ to $I_{N e t}$ after disconnecting of DG. Therefore, the discrimination time between relays R1 and R2 (delta $\mathrm{t} 1$ ), which is equal to the critical time interval (CTI), decreases to delta 2 which is lower than acceptable CTI.

The second state happens when the coordination of OC relays is performed without DG. Connecting DG to the network has no impact on coordination between relays R1 and R2, but may disturb the coordination of relays R2 and R3. As can be seen in Fig. 3, with connecting of DG the fault current passing through relays R2 and R3 increases, and the coordination time interval decreases from delta $t 1$ to delta $\mathrm{t} 2$ which may become lower than acceptable CTI.

The above description is related to the protection challenges in the presence of one DG. Installing more 


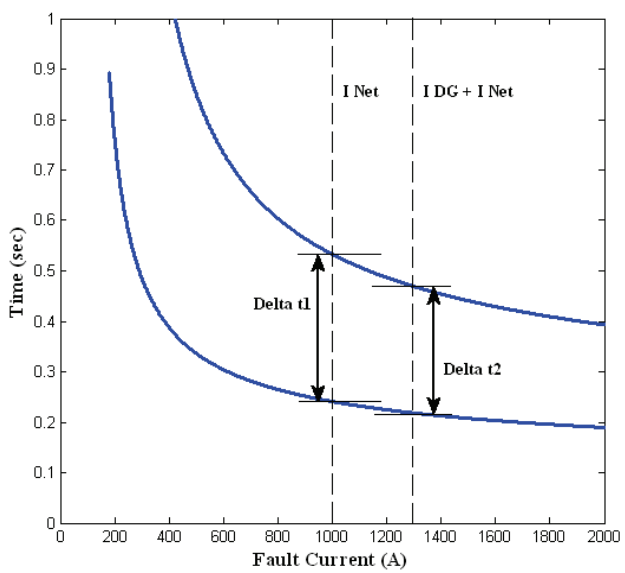

Fig. 3. The time interval between relays R2 \& R3

DGs in different places of the network, numerous misscoordinations occur. Since two states of CADD take place for each DG, the number of possible CADD states for all DGs can be obtained as below:

$$
\text { Number of CADD states }(N)=2^{N D G}
$$

where NDG is the number of DGs. With the increase in the number of CADD states, it is difficult or not possible to obtain a suitable setting for relays to achieve full coordination in all of the CADD states.

In the next section, an adaptive scheme using setting groups of relays is proposed to solve this problem. The setting groups can be changed to maintain the coordination of relays in the new conditions of CADD. The information of CADD condition should be transferred to each relay through communication links.

Since the setting groups of relays are restricted, with the increase of NDG, this problem arises that how all CADD states can be protected.

Due to the different operating conditions, the DGs may encounter partially loss of generation instead of complete loss of generation, which has impact on the injected fault current of DG. The fault current of the synchronous generator is the summation of the transient fault current and the pre-fault load current of the generator [20]. Different operational conditions of DGs have impact on the generator load current which is the small portion of fault current. Therefore, in this condition the fault current is close to rated fault current and lower than it. So, if the OC relay coordination is carried out for two critical conditions, which include connecting and disconnecting of DGs, the coordination for other operating conditions will be achieved.

\section{Proposed Method}

As mentioned in the previous section, the number of

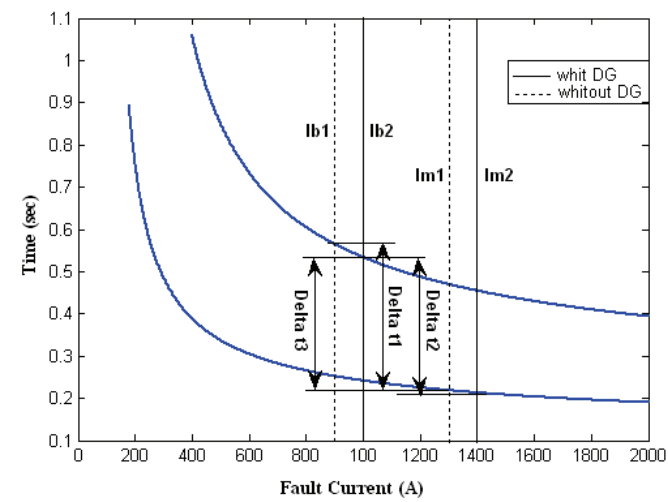

Fig. 4. Time interval between critical main and backup fault current

available setting groups of relays may be lower than the number of CADD states. Therefore, some states should be protected with the same setting groups. Thus a suitable index should be defined to determine and classify the similar states.

\subsection{Classifying index (CI)}

The main and backup currents in two CADD states are different. Therefore, to obtain a proper setting of relays to guarantee the relays coordination of the network in two states of CADD, critical main and backup fault currents are defined. The fault current of relays R1 and R2 in Fig. 1 are changed with connection of DG.

The $\mathrm{P} / \mathrm{B}$ relays' fault current in two states of CADD for fault F2 is shown in Fig. 4. Installing DG, both main and backup fault currents (Im1 and Ib1) increase to (Im2 and Ib2).

So the time interval between main and backup relays decreases from delta $t 1$ to delta $t 2$.

For obtaining the proper setting for two CADD state the critical main and backup fault currents are defined as follows:

$$
\begin{gathered}
\text { Critical main fault current }=\operatorname{Min}\left\{\mathrm{I}_{\mathrm{m} 1}, \mathrm{I}_{\mathrm{m} 2}\right\} \\
\text { Critical backup fault current }=\operatorname{Max}\left\{\mathrm{I}_{\mathrm{b} 1}, \mathrm{I}_{\mathrm{b} 2}\right\}
\end{gathered}
$$

Therefore, the critical main and backup fault currents in Fig. 4 for using in coordination algorithm will be Im1 and $\mathrm{Ib} 2$ respectively. Delta $\mathrm{t} 3$ in Fig. 4 shows the $\mathrm{P} / \mathrm{B}$ relays time interval with using critical fault currents, and it is clear that:

$$
\text { Delta } \mathrm{t} 3 \leq \operatorname{Min}\{\text { Delta } \mathrm{t} 1 \text {, Delta } \mathrm{t} 2\}
$$

Eq. 4 shows that, if the coordination of relays is carried out with critical fault currents, the coordination of each CADD state will be guaranteed. The more these critical fault currents get closer to each other, the value of Delta $t 3$ reduces and the setting of relays should be increased. Thus, 
achieving suitable coordination will be more difficult. The value of Delta $\mathrm{t} 3$ can be used as an index for classifying the states. The characteristics of the relays assumed to be as Eq. 5.

$$
\mathrm{t}_{i}=\left(\frac{\mathrm{A}}{\mathrm{M}_{i}^{\mathrm{c}}-1}+\mathrm{B}\right) \mathrm{TDS}_{i}, \mathrm{M}=\left(\frac{\mathrm{I}_{F i}}{\mathrm{I}_{\mathrm{Pi}}}\right)
$$

where $\mathrm{A}, \mathrm{B}$ and $\mathrm{C}$ are constant parameters. $\mathrm{TDS}_{\mathrm{i}}$ and $\mathrm{I}_{\mathrm{pi}}$ are time dial setting and pickup current setting of $i^{\text {th }}$ relay, respectively. The operating time of relay is a function of $\mathrm{I}_{\mathrm{Fi}}$ which is the fault current flowing through the relay.

In classifying stage, the TDS settings of relays are not accessible. Since the value of Delta $\mathrm{t} 3$ is used only as an index for determining similar states, the TDS values for all relays is assumed to be $\operatorname{TDS}=1$ in the index calculation process. Set of CADD states $\left(\mathrm{Q}_{\mathrm{k}}\right)$ is defined as:

$$
\mathrm{Q}_{k} \subseteq \mathrm{Q}, \quad \mathrm{Q}=\left\{\mathrm{q}_{1}, \mathrm{q}_{2}, \ldots, \mathrm{q}_{N t}\right\}
$$

where $\mathrm{q}_{1}, \mathrm{q}_{2} \ldots$ and $\mathrm{q}_{\mathrm{N}}$ are possible states and $\mathrm{N}$ is defined as Eq. 1. Q contains of all possible states. Qk is the subset of $\mathrm{Q}$ and may contain from one to all of CADD states. Developing the parameter Delta t3, CI for each main/ backup pair relays at the set $\mathrm{Q}_{\mathrm{k}}$ can be defined as below:

$$
\mathrm{CI}_{\mathrm{i}, \mathrm{j}}{ }^{Q_{k}}=\mathrm{t}_{\mathrm{j}}\left(I_{b}{ }^{Q_{k}}\right)-\mathrm{t}_{\mathrm{i}}\left(I_{m}{ }^{Q_{k}}\right) Q_{k} \subseteq Q_{t}
$$

where $t_{i}$ and $t_{j}$ are the operating time of main relay (i) and backup relay (j) for the set $\mathrm{Q}_{\mathrm{k}} \cdot \mathrm{I}_{\mathrm{m}}{ }^{\mathrm{Q}}$ and $\mathrm{I}_{\mathrm{b}}{ }^{\mathrm{Q}}$ are critical fault currents for $(\mathrm{i}, \mathrm{j})$ pair relays and can be obtained according to Eq. 2 and Eq. 3 as below:

$$
\mathrm{I}_{\mathrm{m}}{ }^{Q_{k}}=\min _{n}\left\{\mathrm{I}_{\mathrm{m}}{ }^{\mathrm{q}_{n}}\right\}, \mathrm{I}_{\mathrm{b}}{ }^{Q_{k}}=\max _{n}\left\{\mathrm{I}_{\mathrm{b}}{ }^{\mathrm{q}_{n}}\right\} \quad \mathrm{q}_{n} \in Q_{k}
$$

Thus considering $\mathrm{m}=\left(\mathrm{I}_{\mathrm{m}} / \mathrm{I}_{\mathrm{p}(\mathrm{m})}\right)^{\mathrm{c}}$ and $\mathrm{b}=\left(\mathrm{I} / \mathrm{I}_{\mathrm{p}(\mathrm{b})}\right)^{\mathrm{c}}$ the Eq. 7 can be simplified as:

$$
\mathrm{CI}_{\mathrm{i}, \mathrm{j}}{ }^{Q_{k}}=\mathrm{t}_{\mathrm{j}}\left(I_{b}{ }^{Q_{k}}\right)-\mathrm{t}_{\mathrm{i}}\left(I_{m}{ }^{Q_{k}}\right)=\frac{\mathrm{A}(\mathrm{m}-\mathrm{b})}{(\mathrm{b}-1)(\mathrm{m}-1)}
$$

CI of all P/B relays for Q can be obtained as Eq. 10.

$$
C I^{Q_{k}}=\text { Average }\left\{\mathrm{CI}_{\mathrm{i}, \mathrm{j}}{ }^{Q_{k}}\right\}
$$

CI can be used for evaluating and classifying the set of states. As described for Delta $\mathrm{t} 3$, the small CI shows that the operating time difference between main and backup relays (considering equal TDS=1) are small and the greater TDS value for backup relay is required to achieve the coordination. So, the smaller CI indicates the weakness of results for coordination algorithm. The more the set of
$\mathrm{Q}_{\mathrm{k}}$ contains similar CADD states, the critical $\mathrm{P} / \mathrm{B}$ fault currents have less change, and lead to smaller CI. So, the selection of similar states, for set $\mathrm{Q}_{\mathrm{k}}$, is carried out considering the value of CI. In this method, the calculated $\mathrm{CI}$ for all possible sets of $\mathrm{Q}_{\mathrm{k}}$ is compared, and the suitable classification with greater $\mathrm{CI}$ is selected. In order to achieve an optimum selection result, a classifying method is required to be used, which is described in the next section.

\subsection{Optimal selection of setting groups}

The selection of similar states for limited setting groups, which is carried out considering CI index, is an optimization problem. Since the classification, using defined index (CI) is a nonlinear and discrete problem, intelligent optimization methods such as GA can be suitable for solving this problem.

The assigned setting groups for each states $\left(\mathrm{SG}_{\mathrm{i}}\right)$ are assumed to be the unknown parameters for the optimization problem, which are considered as genomes of the chromosome in the GA. $\mathrm{k}$ can be changed from 1 to $\mathrm{m}$; $\mathrm{m}$ is the number of available setting groups of relays. The structure of the chromosome in GA is shown in Fig. 5.

\begin{tabular}{|c|c|c|c|c|}
\hline State 1 & State 2 & State 3 & $\ldots$ & State $\mathrm{n}$ \\
\hline $\mathrm{SG}_{\mathrm{i}}$ & $\mathrm{SG}_{\mathrm{i}}$ & $\mathrm{SG}_{\mathrm{i}}$ & $\ldots$ & $\mathrm{SG}_{\mathrm{i}}$ \\
\hline
\end{tabular}

Fig. 5. Structure of chromosome

GA generates new chromosomes in each iteration, which includes $\mathrm{SG}_{\mathrm{i}}$ for various states. The CI should be calculated for all similar states which have the same setting groups. An objective function (OF) should be defined for evaluating the goodness of each chromosome. The OF of the method is defined as below:

$$
\mathrm{OF}=\mathrm{a} \times \sum_{\mathrm{k}=1}^{\mathrm{m}} \mathrm{CI}_{\mathrm{k}}+\mathrm{b} \times \operatorname{Min}\left\{\mathrm{CI}_{\mathrm{k}}\right\}
$$

where $\mathrm{CI}_{\mathrm{k}}$ is calculated for combination of all states with the same setting groups of $\mathrm{SG}_{\mathrm{i}}$. The OF of Eq. 11 consists of two terms, which are designed for two different purposes. First term is the summation of calculated $\mathrm{CI}_{\mathrm{k}}$ with weighing factor of a. Since GA selects the chromosomes with the maximum $\mathrm{OF}$, the first term maximizes all $\mathrm{CI}_{\mathrm{k}} \mathrm{s}$. Increasing of $\mathrm{CI}_{\mathrm{k}}$ related to each setting group helps to achieve better coordination. Therefore, the minimum $\mathrm{CI}_{\mathrm{k}}$ is related to worst condition of coordination. The second term of OF is defined for maximizing the minimum $\mathrm{CI}_{\mathrm{k}}$ with weighing factor of $b$. With the control parameters $a$ and $b$ the priority of two terms can be determined.

\subsection{Coordination algorithm}

Different methods are proposed for optimal coordination of ovecurrent relays in interconnected networks. Here the 
coordination of relays is fulfilled by the method mentioned in [21] using GA. The OF is as below:

$$
\begin{gathered}
\text { Minimized : } O F=\sum_{i=1}^{N}\left(t_{i}\right) \\
\text { Subject to }: t_{i}-t_{j} \geq C T I \quad \forall\left(q_{i} j\right) \in \\
T D S_{i}^{\min } \leq T D S_{i} \leq T D S_{i}^{\max }
\end{gathered}
$$

where $t_{i}$ is the operating time of $i^{\text {th }}$ relay for the fault near to the circuit breaker $(\mathrm{CB})$ of that relay and $\Omega$ is the set of main/backup relay pairs. $t_{i}$ and $t_{j}$ indicate the operating times of main and backup relays, respectively, for a fault near to the $\mathrm{CB}$ of the main relay. $\mathrm{CTI}$ is the critical time interval between main and backup relays, which is assumed to be 0.3 second in this paper. $\operatorname{TDS}_{\mathrm{i}}{ }^{\mathrm{min}}$ and $\mathrm{TDS}_{\mathrm{i}}{ }^{\max }$ are the lower and upper limits of $\operatorname{TDS}_{\mathrm{i}}$, respectively.

The coordination algorithm should be modified to obtain the optimal setting of relays for $\mathrm{Q}_{\mathrm{k}}$ which is valid for all

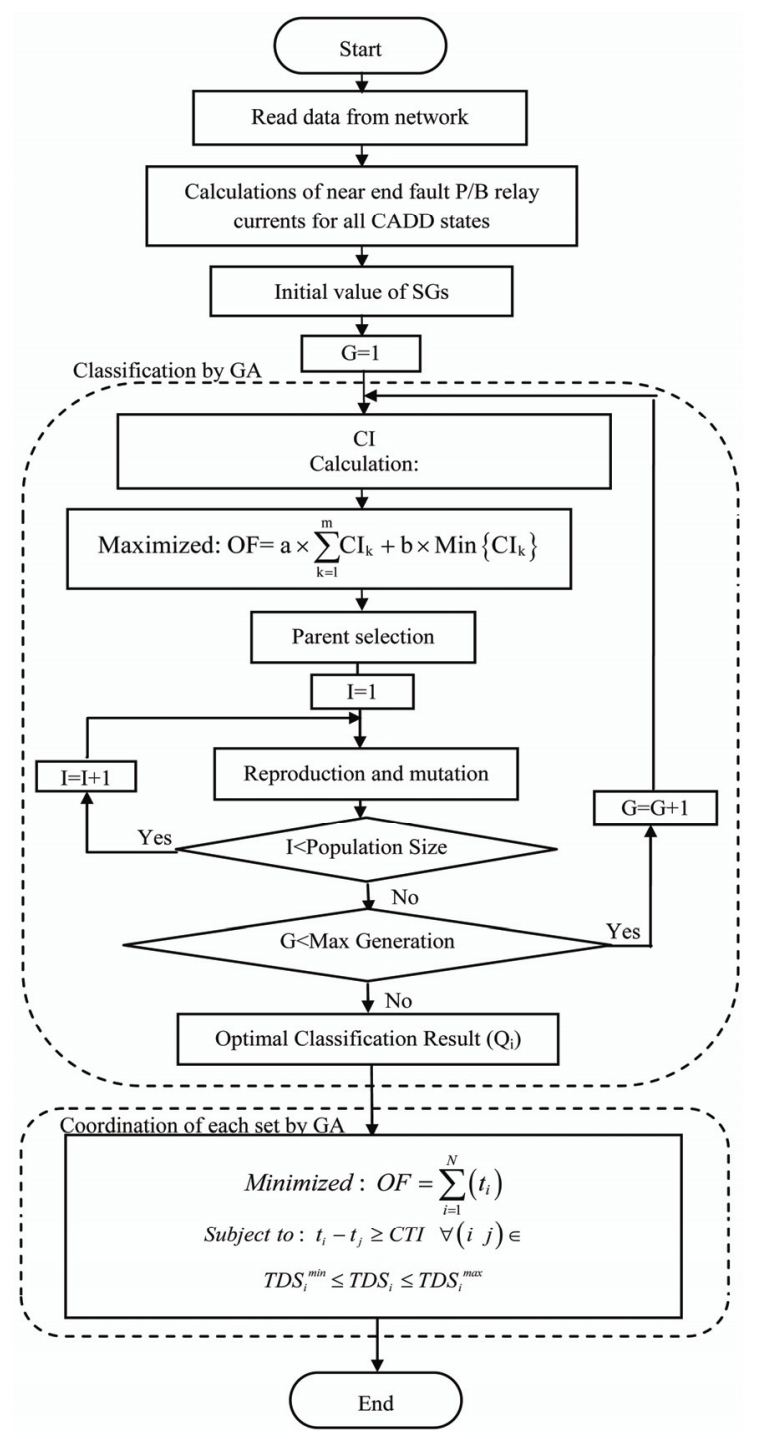

Fig. 6. Flow diagram of algorithm states of $\mathrm{Q}_{\mathrm{k}}$. So, the Eq.13 is modified as below:

$$
t_{i}^{q}-t_{j}^{q} \geq C T I \quad \forall(i, j) \in \Omega_{q} \quad \forall q \in Q_{k}
$$

where $\Omega_{q}$ is the set of main/backup relay pairs in the $\mathrm{q}^{\text {th }}$ state of CADD. $\mathrm{t}_{\mathrm{i}}^{\mathrm{q}}$ and $\mathrm{t}_{\mathrm{j}}{ }_{\mathrm{q}}^{\mathrm{q}}$ are the operating times of primary and backup relays, respectively, in the $\mathrm{q}^{\text {th }}$ network topology.

The coordination algorithm is carried out for each set using the OF of Eq. 13 and the results are used for each related setting group. The flow diagram of the algorithm is shown in Fig. 6.

For implementation of the proposed adaptive method, a communication system between DGs and relays is needed. Relays receive the states of DGs by the communication links and the setting groups of relays are modified using a logic circuit installed on relays.

\section{Simulation and Results}

The case study in this paper is IEEE 30 buses system, which can be considered as a meshed sub-transmission / distribution system. It consists of 30 buses (132 and $33 \mathrm{kV}$ buses), 37 lines, 6 generators, 4 transformers, and 86 OC relays. The distribution section of network that will be studied here, is shown in Fig. 7. The under study power distribution system is fed from three primary distribution substations $132 / 33 \mathrm{KV}$ at buses 1,6 , and 13 . The generator, transmission lines, and transformer information are given in reference [22].

Totally, 38 directional overcurrent relays are considered for the network, which are installed at each end of lines. The characteristics of the relays are as Eq. 5 in which A, B, and $\mathrm{C}$ are $0.0515,0.114$, and 0.02 , respectively.

The location of DG installation is determined considering the parameters as load demand and network topology. In

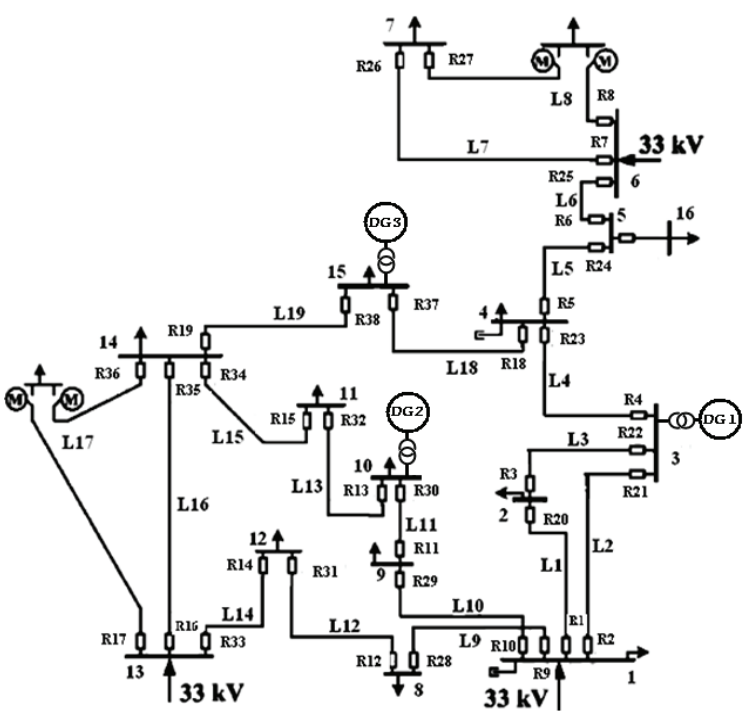

Fig. 7. IEEE 30 bus distribution network 
Table 1. M/B fault currents of relays $36 \& 38$ and $18 \& 4$ for 8 CADD states

\begin{tabular}{|c|c|c|c|c|c|c|c|}
\hline States & Connected DGs & 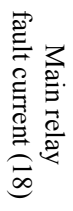 & 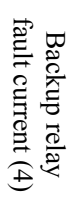 & 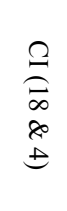 & 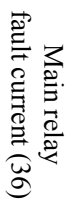 & 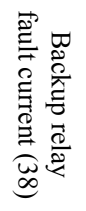 & 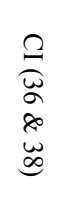 \\
\hline State 1 & DG1+DG2+DG3 & 5031 & 3314 & 1.10 & 6614 & 19440 & 1.91 \\
\hline State 2 & DG1+DG2 & 4971 & 3255 & 1.12 & 6111 & 1484 & 2.77 \\
\hline State 3 & DG1+DG3 & 4899 & 3182 & 1.16 & 6227 & 1905 & 1.93 \\
\hline State 4 & DG2+DG3 & 4719 & 3002 & 1.27 & 6420 & 1867 & 2.02 \\
\hline State 5 & DG1 & 4833 & 3116 & 1.20 & 5715 & 1441 & 2.83 \\
\hline State 6 & DG2 & 4655 & 2938 & 1.32 & 5902 & 1398 & 2.99 \\
\hline State 7 & DG3 & 4572 & 2855 & 1.38 & 6013 & 1824 & 2.03 \\
\hline State 8 & No DG & 4501 & 2784 & 1.43 & 5485 & 1349 & 3.08 \\
\hline \multicolumn{2}{|c|}{$\begin{array}{l}\text { Critical fault current for all } \\
\text { states (one setting group) }\end{array}$} & 4501 & 3314 & 1.04 & 5485 & 1944 & 1.75 \\
\hline
\end{tabular}

this paper, 3 DG is assumed to be added at buses 3,10, and 15 with the capacities of 3 MVA which the transient reactance of them is 0.1 based on their capacities. The chosen DG technology is a synchronous type, operating nominally at 0.9 lagging power factor.

The DGs are practically connected to the distribution network through the transformers which are assumed to have 10 MVA capacity and 0.05 p.u. reactance based on their capacities. This network has 3 DGs. Therefore, according to Eq. 1 the number of CADD states will be 8 . Since the available setting groups of new numerical relays is equal to 4 , in this project the number of available setting group for all relays is assumed to be 4 . As mentioned above, the 8 CADD states should be assigned to 4 setting groups using defined $\mathrm{CI}$.

The sample network contains $62 \mathrm{P} / \mathrm{B}$ relays. To obtain the $\mathrm{CI}$, the current passing through all $\mathrm{P} / \mathrm{B}$ relays for the fault close to the circuit breaker of main relays should be calculated for 8 states. For instance, the P/B fault currents of two pairs of relays for fault close the $\mathrm{CB}$ of main relay in 8 CADD states is given in Table 1 .

It can be seen from Table 1, with connecting or disconnecting of DGs the M/B fault current of relays 18 \& 4 change, and it is difficult to obtain one suitable setting for all states. The calculated CI for M/B fault current of relays 18 \& 4 shows the best CI in the state $8(1.43)$ and the worst $\mathrm{CI}$ in the state $1(1.10)$. The last row of Table 1 shows the $\mathrm{M} / \mathrm{B}$ critical fault currents for the combination of all CADD states which are the minimum main fault current and the maximum backup fault current. The critical M/B fault currents as shown in Fig. 4 decrease the time interval of M/B relays, which leads to lower CI (1.05). To achieve the coordination with critical fault current the setting of backup relay should be increased, which cause to increase the operating time of relays and maybe the coordination cannot be achieved.

As can be seen from sixth column of Table 1, the main fault current of relays $36 \& 38$ (far from DG1) have low
Table 2. CI for sets which contain one state or two states

\begin{tabular}{c|c|c|c|c|c|c|c|c}
\hline State & 1 & 2 & 3 & 4 & 5 & 6 & 7 & 8 \\
\hline 1 & 1.82 & 1.75 & 1.74 & 1.76 & 1.66 & 1.69 & 1.68 & 1.59 \\
\hline 2 & 1.75 & 1.96 & 1.79 & 1.82 & 1.87 & 1.89 & 1.80 & 1.79 \\
\hline 3 & 1.74 & 1.79 & 1.98 & 1.78 & 1.90 & 1.76 & 1.91 & 1.82 \\
\hline 4 & 1.76 & 1.82 & 1.78 & 2.15 & 1.79 & 2.07 & 2.06 & 1.97 \\
\hline 5 & 1.66 & 1.87 & 1.90 & 1.79 & 2.16 & 1.92 & 1.99 & 2.09 \\
\hline 6 & 1.69 & 1.89 & 1.76 & 2.07 & 1.92 & 2.44 & 2.14 & 2.34 \\
\hline 7 & 1.68 & 1.80 & 1.91 & 2.06 & 1.99 & 2.14 & 2.35 & 2.26 \\
\hline 8 & 1.59 & 1.79 & 1.82 & 1.97 & 2.09 & 2.34 & 2.26 & 2.74 \\
\hline
\end{tabular}

dependency to connecting of DG1. So, for relays $36 \& 38$ the main fault current in states 1 and 8 are similar to states 4 and 5 respectively, because of the lower impact of DG1. But the backup fault current of relays $36 \& 38$ (far from DG2) have low dependency to the connecting of DG2, so the backup fault current of states 1 and 8 are similar to 3 and 6.

For obtaining the similar state for state 1, the minimum fault current of main relay and the maximum fault current of backup relay should be calculated for all combinations. The maximum backup fault current is 1994.0. Therefore, the main fault current is significant and the state 4 is more similar to state 1 than state 3 . The CI can be calculated for each $\mathrm{M} / \mathrm{B}$ relays using Eq. 9, and the average of $\mathrm{CI}$ for all $\mathrm{M} / \mathrm{B}$ relays (Eq. 10) is used to determine the similar states. After calculation of M/B fault currents, CI can be determined for all possible sets of states. For better description, CI is obtained for sets which contain one state or two states and the result is given in Table 2. The diagonal components are related to single states and the other components show the CI for combination of two states. The more the similar the two states are, the greater the CI will be. In the other word, CI shows the correlation of CADD states.

For example, CI for the combination of state 7 with state 2 is lower than the CI obtained for combination of state 7 with states 3 or 4 . That is because sates 3,4 and 7 include the presence of DG3 (Table 1) while the state 2 has not participated in this property. This rule can be observed for $\mathrm{CI}$ of other sets. Table 2 shows that CI of one state alone (diagonal components) is greater than CI for combination of the same state with another state.

GA using the OF of Eq.11 is applied for classification of CADD states. In each iteration, GA produces some chromosomes including the setting groups. For obtaining the $\mathrm{OF}$ in each iteration, the CI's of sets are calculated using the $\mathrm{P} / \mathrm{B}$ relays fault current by equations 9 and 10 . The chromosome, which has the maximum OF, is selected as best solution.

The value of control parameters of Eq.11 is assumed to be 1 and 10 for $a$ and $b$ respectively. This selection of control parameters gives the higher priority for maximizing the minimum CI which can help in coordination of the worst case. The algorithm considering 4 available setting groups has been run and the output is given in Table 3 . 
Table 3. Output of GA considering 4 setting groups

\begin{tabular}{c|c|c|c|c|c|c|c}
\hline State 1 & State 2 & State 3 & State 4 & State 5 & State 6 & State 7 & State 8 \\
\hline SG1 & SG2 & SG4 & SG3 & SG4 & SG3 & SG4 & SG4 \\
\hline
\end{tabular}

Table 4. The calculated CI for each setting group

\begin{tabular}{|c|c|c|c|c|c|c|c|}
\hline 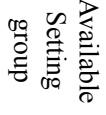 & & SG1 & SG2 & SG3 & SG4 & SG5 & 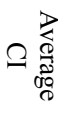 \\
\hline \multirow{2}{*}{$2 \mathrm{SGs}$} & Set $Q_{k}$ & $1,3,4$ & $2,5,6,7,8$ & & & & \\
\hline & $\mathrm{CI}$ & 1.71 & 1.73 & & & & 1.72 \\
\hline \multirow{2}{*}{3 SGs } & Set $Q_{k}$ & 1 & $2,4,6$ & $3,5,7,8$ & & & \\
\hline & $\mathrm{CI}$ & 1.82 & 1.78 & 1.86 & & & 1.82 \\
\hline \multirow{2}{*}{4 SGs } & Set $Q_{k}$ & 1 & 2 & 4,6 & $3,5,7,8$ & & \\
\hline & $\mathrm{CI}$ & 1.82 & 1.96 & 2.07 & 1.82 & & 1.91 \\
\hline \multirow{2}{*}{$5 \mathrm{SGs}$} & Set $Q_{k}$ & 1 & 2 & 4,6 & 3,5 & 8 & \\
\hline & $\mathrm{CI}$ & 1.82 & 1.96 & 1.94 & 2.01 & 2.77 & 2.10 \\
\hline
\end{tabular}

From Table 3, the states with similar setting groups and the calculated $\mathrm{CI}$ for each setting group are listed in Table 4. Also, the result of algorithm considering 2, 3 and 5 available setting groups has been calculated and are shown in Table 4 for comparison.

As can be seen from Table 4, each setting group related to one set $\left(Q_{k}\right)$ that contains one or more CADD states. The optimal classification of states has been carried out by using the parameter CI which is calculated and given in the table for each set of $\mathrm{Q}_{\mathrm{k}}$. By increasing the number of available setting group, the average value of parameter CI increases.

GA using OF of Eq. 12 is applied to find the best setting of relays for each setting group. For illustration the effectiveness of the new method, the results of coordination for two cases considering 2 and 4 available setting groups are compared to the result of a case in which the fixed setting is applied (none-adaptive method). In "none-adaptive method" the adaptive method is not used for relay coordination and the fixed setting of relays are considered for all states of network. So, the fixed setting of relays lead to greater operating time of relays, or in some networks the full coordination of relays may not be achieved.

The TDS setting of relays, and CI for three cases are given in Table 5. The average of TDSs and the average of operation time of relays for close in fault is considered for comparing three cases. Column 2 shows the TDS setting of relays by using fixed setting group (noneadaptive). In this method, the constraints of all states should be satisfied with one setting using Eq. 15. Also, the result of adaptive methods with 2 SGs and 4 SGs are given in the next columns of Table 5, respectively. As can be seen, the maximum average of TDSs (0.93) and the maximum average of operating times of relays (1.22) are related to none-adaptive method with the CI parameter of 1.59. By using the new adaptive method, the average of TDSs and the average of operating times of relays
Table 5. Comparison of the results of relay setting in 3 methods

\begin{tabular}{|c|c|c|c|c|c|c|c|}
\hline \multirow{3}{*}{$\begin{array}{l}Z \\
0 \\
\ddot{0} \\
0 \\
\stackrel{2}{2}\end{array}$} & \multirow{3}{*}{$\begin{array}{c}\text { Non- } \\
\text { adaptive } \\
\text { method } \\
\text { with one } \\
\text { SG }\end{array}$} & \multicolumn{2}{|c|}{$\begin{array}{l}\text { Adaptive method } \\
\text { with two SGs }\end{array}$} & \multicolumn{4}{|c|}{$\begin{array}{l}\text { Adaptive method } \\
\text { with four SGs }\end{array}$} \\
\hline & & SG1 & SG2 & SG1 & $\mathrm{SG} 2$ & SG3 & SG4 \\
\hline & & $1,3 \& 4$ & $\begin{array}{c}2,5,6 \\
7 \& 8\end{array}$ & 1 & 2 & $4 \& 6$ & $\begin{array}{c}3,5,7 \\
\& 8\end{array}$ \\
\hline R 1 & 0.90 & 0.99 & 0.84 & 0.56 & 0.86 & 0.86 & 0.85 \\
\hline R 2 & 1.02 & 1.03 & 0.87 & 0.52 & 0.67 & 0.53 & 1.02 \\
\hline R 3 & 0.66 & 0.73 & 0.61 & 0.46 & 0.66 & 0.63 & 0.65 \\
\hline R 4 & 0.58 & 0.65 & 0.52 & 0.36 & 0.60 & 0.53 & 0.49 \\
\hline R 5 & 0.43 & 0.52 & 0.38 & 0.20 & 0.46 & 0.41 & 0.36 \\
\hline R 6 & 0.23 & 0.26 & 0.21 & 0.16 & 0.28 & 0.24 & 0.20 \\
\hline R 7 & 0.17 & 0.21 & 0.16 & 0.12 & 0.16 & 0.18 & 0.15 \\
\hline R 8 & 0.13 & 0.15 & 0.12 & 0.86 & 0.12 & 0.13 & 0.12 \\
\hline R 9 & 1.72 & 1.40 & 1.21 & 0.88 & 1.10 & 0.96 & 1.09 \\
\hline R 10 & 1.66 & 1.41 & 1.39 & 0.69 & 0.95 & 0.95 & 2.00 \\
\hline R 11 & 1.39 & 1.16 & 1.16 & 0.65 & 0.77 & 0.73 & 0.91 \\
\hline R 12 & 1.41 & 1.10 & 0.95 & 0.59 & 0.86 & 0.73 & 0.84 \\
\hline R 13 & 1.16 & 0.96 & 0.94 & 0.48 & 0.65 & 0.53 & 0.71 \\
\hline R 14 & 1.15 & 0.83 & 0.73 & 0.43 & 0.68 & 0.52 & 0.65 \\
\hline R 15 & 0.95 & 0.67 & 0.66 & 0.72 & 0.48 & 0.37 & 0.55 \\
\hline R 16 & 2.00 & 1.31 & 1.13 & 0.22 & 1.01 & 0.82 & 1.04 \\
\hline R 17 & 0.49 & 0.38 & 0.31 & 1.34 & 0.32 & 0.22 & 0.28 \\
\hline R 18 & 1.54 & 1.33 & 1.40 & 0.64 & 1.35 & 1.37 & 1.38 \\
\hline R 19 & 2.00 & 1.05 & 1.03 & 0.45 & 0.72 & 0.66 & 1.08 \\
\hline R 20 & 0.89 & 0.75 & 0.71 & 0.27 & 0.56 & 0.34 & 0.97 \\
\hline R 21 & 0.55 & 0.52 & 0.45 & 0.64 & 0.37 & 0.12 & 0.60 \\
\hline R 22 & 1.24 & 1.06 & 1.02 & 0.52 & 0.75 & 0.55 & 1.28 \\
\hline R 23 & 1.06 & 1.02 & 0.90 & 0.86 & 0.61 & 0.54 & 1.06 \\
\hline R 24 & 1.03 & 0.89 & 0.94 & 1.01 & 0.89 & 0.95 & 0.92 \\
\hline R 25 & 1.21 & 1.08 & 1.10 & 0.05 & 1.06 & 1.13 & 1.07 \\
\hline R 26 & 0.05 & 0.06 & 0.05 & 0.05 & 0.05 & 0.05 & 0.05 \\
\hline R 27 & 0.05 & 0.06 & 0.05 & 0.47 & 0.05 & 0.05 & 0.05 \\
\hline R 28 & 0.84 & 0.75 & 0.75 & 0.36 & 0.50 & 0.52 & 0.96 \\
\hline R 29 & 0.33 & 0.54 & 0.48 & 0.51 & 0.41 & 0.26 & 0.32 \\
\hline R 30 & 0.51 & 0.85 & 0.77 & 0.60 & 0.59 & 0.42 & 0.47 \\
\hline R 31 & 1.03 & 0.95 & 0.92 & 0.55 & 0.65 & 0.65 & 1.13 \\
\hline R 32 & 0.70 & 1.04 & 0.97 & 0.77 & 0.62 & 0.58 & 0.63 \\
\hline R 33 & 1.26 & 1.20 & 1.18 & 0.70 & 0.82 & 0.89 & 1.33 \\
\hline R 34 & 2.00 & 1.36 & 1.17 & 0.52 & 0.80 & 0.75 & 0.82 \\
\hline R 35 & 0.84 & 0.85 & 0.85 & 0.05 & 0.58 & 0.54 & 0.85 \\
\hline R 36 & 0.05 & 0.06 & 0.06 & 0.46 & 0.05 & 0.05 & 0.05 \\
\hline R 37 & 0.93 & 0.91 & 0.82 & 1.20 & 0.53 & 0.46 & 0.91 \\
\hline R 38 & 1.33 & 1.34 & 1.20 & 0.56 & 1.20 & 1.20 & 0.85 \\
\hline \multirow{2}{*}{$\begin{array}{c}\text { Average } \\
\text { TDS }\end{array}$} & \multirow{2}{*}{0.93} & 0.83 & 0.77 & 0.71 & 0.62 & 0.56 & 0.75 \\
\hline & & \multicolumn{2}{|c|}{0.80} & \multicolumn{4}{|c|}{0.64} \\
\hline \multirow{2}{*}{$\begin{array}{c}\text { Average } \\
\text { Time }\end{array}$} & \multirow{2}{*}{1.22} & 1.08 & 0.97 & 0.83 & 0.74 & 0.68 & 0.89 \\
\hline & & \multicolumn{2}{|c|}{1.03} & \multicolumn{4}{|c|}{0.78} \\
\hline \multirow{2}{*}{$\mathrm{CI}$} & \multirow{2}{*}{1.59} & 1.71 & 1.73 & 1.82 & 1.96 & 2.07 & 1.82 \\
\hline & & 1. & & \multicolumn{4}{|c|}{1.91} \\
\hline
\end{tabular}

decrease. Comparing the TDS setting and the operating time of relays in Table 5, it is clear that, the result of coordination algorithm by using $4 \mathrm{SG}$ is better than the same result by using 2 SGs and one SG. The parameter CI also is given in Table 5 for comparing the results. The minimum average of TDS is 0.56 (with the minimum operating time of 0.68 ) in column 7 which is related to maximum CI (2.09).

In column 1, none-adaptive method, the TDSs of some relays (for example, relay R16) are high value (2.0) and 
lead to high operating times. Furthermore, since the maximum value of TDS is assumed to be 2 , by increasing the size or number of DGs the full coordination of relays may be unobtainable. For illustration of the efficiency, the new method is compared to previous methods for various DG capacities. The compared methods are mentioned below:

\section{Case 1: Non-adaptive method with one SG}

Case 2: Adaptive method of [19] with 4 SGs

Case 3: New Adaptive method with 2 SGs

Case 4: New Adaptive method with 4 SGs

The simulation is carried out on IEEE 30 bus distribution network which the type and the location of DGs and relays are assumed as previous simulation. The simulation is performed for various DG size values to determine the coordination range of each method. The results are given in Fig. 8. The result shows that for the DG size lower than 3.1 MVA, the non-adaptive method with fixed SG (case 1) leads to full coordination of relays. But for DG size greater than 3.1 MVA this method cannot satisfy all coordination constraints.

As can be seen, in case 2 ([19]) for the DG size greater than 5.8 MVA the method has some limitations, and requires more than $4 \mathrm{SGs}$ to achieve full coordination of relays. As described in section $\mathrm{I}$, this method is based on changing the setting groups of relays separately in the iterative algorithm. Since the setting of one relay is not independent from others, changing the setting of one relay will cause to disturb the coordination with other

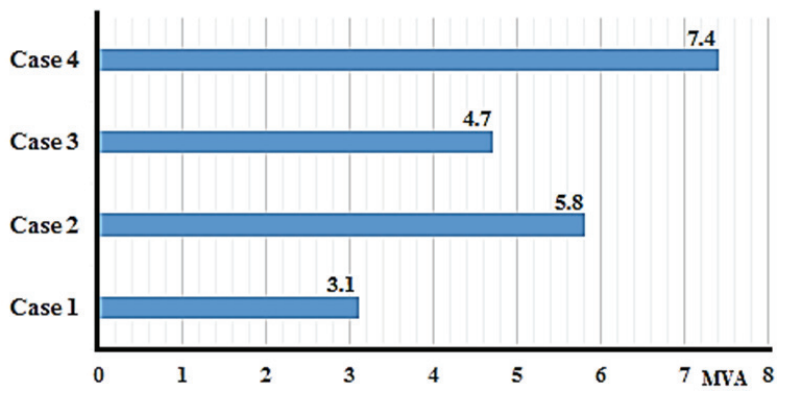

Fig. 8. The maximum sizes of DG's to maintain full coordination of relays for 4 cases

Table 6. Coordination of relays for 4 studied cases with various number of installed DGs

\begin{tabular}{c|c|c|c|c}
\hline $\begin{array}{c}\text { DG } \\
\text { Numbers }\end{array}$ & $\begin{array}{c}\text { Method 1: } \\
\text { fixed SG } \\
\text { non-adaptive }\end{array}$ & $\begin{array}{c}\text { Method 2: } \\
\text { 4 SG Ref } \\
{[19]}\end{array}$ & $\begin{array}{c}\text { Method 3: } \\
\text { New } \\
\text { Adaptive } \\
2 \text { SG }\end{array}$ & $\begin{array}{c}\text { Method 4: } \\
\text { New } \\
\text { Adaptive } \\
\text { 4 SG }\end{array}$ \\
\hline $\begin{array}{c}\text { DG at } \\
\text { Bus 3 }\end{array}$ & $\begin{array}{c}\text { Full } \\
\text { Coordination }\end{array}$ & $\begin{array}{c}\text { Full } \\
\text { Coordination }\end{array}$ & $\begin{array}{c}\text { Full } \\
\text { Coordination }\end{array}$ & $\begin{array}{c}\text { Full } \\
\text { Coordination }\end{array}$ \\
\hline $\begin{array}{c}\text { 2 DGs at } \\
\text { buses 3\&10 }\end{array}$ & $\begin{array}{c}\text { Some Miss- } \\
\text { coordination }\end{array}$ & $\begin{array}{c}\text { Full } \\
\text { Coordination }\end{array}$ & $\begin{array}{c}\text { Full } \\
\text { Coordination }\end{array}$ & $\begin{array}{c}\text { Full } \\
\text { Coordination }\end{array}$ \\
\hline $\begin{array}{c}\text { 3 DGs at } \\
\text { buses 3, 10 } \\
\& 15\end{array}$ & $\begin{array}{c}\text { Some Miss- } \\
\text { coordination }\end{array}$ & $\begin{array}{c}\text { Some Miss- } \\
\text { coordination }\end{array}$ & $\begin{array}{c}\text { Some Miss- } \\
\text { coordination }\end{array}$ & $\begin{array}{c}\text { Full } \\
\text { Coordination }\end{array}$ \\
\hline
\end{tabular}

relays. So this method needs more SGs to achieve full coordination.

In the case 3, which is related to the new adaptive method with 2 SGs, full coordination of relays can be achieved for the maximum DG size of 4.7 MVA. By increasing the number of SG in case 4 (4 SGs), the full coordination of relays can be achieved for maximum DG size of 7.4 MVA.

The other comparison is carried out for various numbers of installed DGs. Table 6 shows the relays coordination status in 4 mentioned methods with changing the number of installed DGs. The network parameters are considered as previous simulation with one change in the Size of all DGs which is assumed to be 6 MVA.

As can be seen from Table 6, increasing the number of installed DGs from 1 to 3 , the complexity of coordination problem is increased. The result of case 1 shows that, by installing $1 \mathrm{DG}$ at bus 3 the full coordination is achieved. But miss-coordination is appeared with adding the DG at bus 10 . In cases 2 and 3, which adaptive methods is used, full coordination of relays can be obtained for the network with installing 2 DGs. But, installing one more DG at bus 15 , cause to miss-coordination in these methods. The results show that using method 4 , the full coordination is achieved for the problem of adaptive relay setting in the presence of 3 installed DGs.

The results demonstrate the efficiency of the proposed classification method for optimal adaptive coordination of overcurrent relays. It can be seen from Table 5, the average of operating time of relays in new method (adaptive method) is lower in comparer to none-adaptive method. So, the new method is fast. In the other hand, Fig. 8 and Table 6 shows that with increasing the size and the number of DGs respectively, the none-adaptive method (case 1) miss the full coordination of relays and the adaptive method is needed to maintain the coordination of relays. Therefore the new method is more secure respect to old method.

\section{Conclusion}

In this paper, an adaptive scheme based on online setting group selection is proposed for restoring the overcurrent relays coordination in various CADD states. Since the number of available setting groups is restricted, it is not possible to cover all the possible CADD states with separate setting groups. Therefore, a classification method is proposed to determine similar states which can be adapted with the same setting group. For obtaining optimal classification results, which guarantees the coordination in each group, a suitable classifying index is defined. GA uses this CI for obtaining the states assigned for each setting group. A new coordination method with modified OF is proposed to obtain the relays setting for combination of states in each setting group. 
The method is applied to IEEE 30 bus sample network, and the results are compared to the results of a supposed method without optimal classification and the results of previous methods. From the coordination evaluation of the new obtained results, it has been revealed that the approach which described in the paper is efficient and successful.

\section{References}

[1] W. El-Khattam, M. A. A. Salama, "Distributed generation technologies, definitions and benefits," Electric Power Systems Research; vol. 71, no. 2, pp. 119-128, Oct. 2014.

[2] P. Barker, R.W. De Mello, "Determining the Impact of Distributed Generation on Power Systems: Part 1-Radial power systems," in Proc. IEEE Power Energy Society Summer Power Meeting, pp. 16451658, 2000.

[3] N. Hadjsaid, J. F. Canard, F. Dumas, "Dispersed generation impact on distribution networks," IEEE Computer Applications in Power, vol. 12, no. 2, pp. 22-28, Apr. 1999.

[4] J. A. Sa'ed, S. Favuzza, M. G. Ippolito, F. Massaro. "Investigating the effect of distributed generators on traditional protection in radial distribution systems," IEEE conference PowerTech, pp. 1-6, 2013.

[5] Kauhaniemi K, Kumpulainen L. Impact of distributed generation on the protection of distribution networks, in Proc. IEEE International Conference on Developments in Power System Protection, pp. 315318, 2004.

[6] H. Yang, F. Wen, G. Ledwich, "Optimal coordination of overcurrent relays in distribution systems with distributed generators based on differential evolution algorithm," International Transactions on Electrical Energy Systems," vol. 23, pp. 1-12, 2013.

[7] G. Tang, M. R. Iravani, "Application of a fault current limiter to minimize distributed generation impact on coordinated relay protection," in Proc. International Conference on Power Systems Transients, pp. 19-23, 2005.

[8] W. El-Khattam, T. S. Sidhu, "Restoration of Directional Overcurrent Relay Coordination in Distributed Generation Systems Utilizing Fault Current Limiter," IEEE Transactions on Power Delivery, vol. 23, no. 2, pp. 415-425, Apr. 2008.

[9] A. Agheli, H. A. Abyaneh, R. Mohammadi, H. Hashemi, "Reducing of the impact of DG in distribution networks protection using fault current limiters," in Proc. Fourth International Power Engineering and Optimization Conference, Malaysia, 2010, pp. 298303.

[10] R. Mohammadi, H. A. Abyaneh, A. Agheli, H. Rastegar, "Overcurrent relays coordination considering transient behavior of fault current limiter and distributed generation in distribution power network," IET Generation, Transmission \& Distribution, vol. 5 no. 9, pp. 903-911, Sep. 2011.

[11] S. M. Brahma, A. A. Girgis, "Development of adaptive protection scheme for distribution systems with high penetration of distributed generation," IEEE Transaction on Power Delivery, vol. 19, no. 1, pp. 5663, Jan. 2004.

[12] M. Baran I. El-Markabi, "Adaptive over current protection for distribution feeders with distributed generators," in Proc. IEEE Power Systems Conference and Exposition, Oct. 2004, pp. 715-719.

[13] S. M. Brahma, A. A. Girgis, "Microprocessor-based reclosing to coordinate fuse and recloser in a system with high penetration of distributed generation," in Proc. IEEE Power Energy Society Winter Meeting, 2002, pp. 453-458.

[14] P. Mahat, C. Zhe, B. Bak-Jensen, C. L. Bak. “A simple adaptive overcurrent protection of distribution systems with distributed generation," IEEE Transactions on Smart Grid, vol. 2, no. 3, pp. 428-437, Jun. 2011.

[15] O.A. Amoda, N.N. Schulz, "An Adaptive Protection Scheme for Shipboard Power Systems," Electric Ship Technologies Symposium, Arlington, 2007, pp. 225230.

[16] H. Wan, K. K. Li, K. P. Wong, "Multi-agent application of substation protection coordination with distributed generators," European Transactions on Electrical Power, vol. 16, no. 5, pp. 495-506, sep. 2006.

[17] H. Cheung, A. Hamlyn, Y. Cungang, R. Cheung, "Network-based adaptive protection strategy for feeders with distributed generations," in Proc, IEEE Canada Electric Power Conference, 2007, pp. 514519.

[18] F. Coffele, C. Booth, A. Dysko. "An Adaptive Overcurrent Protection Scheme for Distribution Networks," IEEE Transactions on Power Delivery, vol. 30 no. 2, pp. 561-568, Feb. 2014.

[19] W. El-Khattam, T. S. Sidhu, "Resolving the Impact of Distributed Renewable Generation On Directional Overcurrent Relay Coordination: A Case Study," IET Generation, Transmission \& Distribution, vol. 3 no. 4, pp. 415-425, 2009.

[20] J. D. Glover, M. S. Sarma, T. J. Overbye, Power System Analysis and Design, Global Engineering, USA, 2012.

[21] F. Razavi, H. A. Abyaneh, M. Al-dabbagh, R. Mohammadi, H. Torkaman, "A new comprehensive genetic algorithm method for optimal overcurrent relays coordination," Electric Power Systems Research, vol. 78, pp. 713-720, 2008.

[22] Power system test cases, available online at: www.ee.washington.edu/resesrch/pstca. 


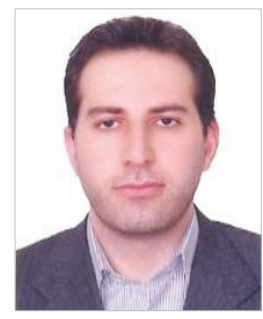

Reza Mohammadi was born in 1981 in Tabriz, Iran. He received the M.Sc. and Ph.D degree in electrical engineering from Amirkabir University of Technology (AUT) in 2007 and 2011 respectively. Currently, he is an assistant professor with the Department of Electrical Engineering, Shahid Beheshti University, Iran, working in the area of the power system protection.

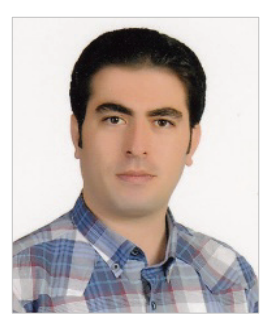

Meysam Farrokhifar was born in Tabriz, Iran. He received the B.Sc. and M.Sc. degrees in electrical engineering from University of Tabriz, Iran, in 2004 and 2007, respectively, and $\mathrm{PhD}$ degree in electrical engineering from Politecnico di Milano, Italy, in 2014. He joined Azad University of Heris, Iran as an academic staff in 2014. His research interests are power system optimization, energy management, electrical machines and transformers.

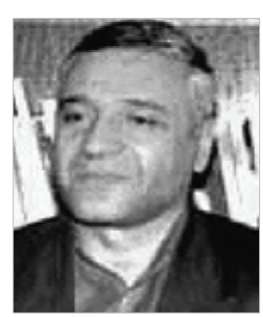

Hossein Askarian Abyaneh was born in Abyaneh, on 1953. He received M.S. degree and Ph.D. degree in electrical power system engineering from the University of Manchester Institute of Science and Technology, Manchester, U.K., in 1985 and 1988, respectively. Currently, he is a professor with the Department of Electrical Engineering, Amirkabir University of Technology, Iran, working in the area of the relay protection and power quality.

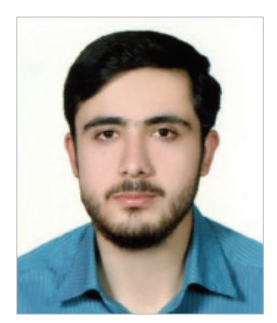

Ehsan khoob was born in Iran in 1988. $\mathrm{He}$ received his B.Sc. degree in Electrical Engineering in 2010 from Shahid Chamran University, and his M.Sc. degree in Power System Protection Engineering from Amirkabir University, in 2012. Now, he is Ph.D. student of power system engineering in Shahid Chamran University, Ahwaz, Iran. His main research interest is Adaptive Power System Protection and Distributed Generation. 